\title{
The Diagnostic Value of Ultrasound Elastography and Colour Doppler Ultrasonograhy in Predicting Malignancy in Intermediate Thyroid Nodules
}

\author{
ALSHAYMAA ZAKARIA MAHMOUD, M.D. \\ The Department of Radiology, Faculty of Medicine, Tanta University
}

\begin{abstract}
Background: Nodules of thyroid gland are very common and the majority of them are benign. Sonography has many favorable features, such as detection of non-palpable nodules, estimation of size and volume of the nodule and guidance for Fine Needle Biopsy (FNB). High-resolution ultrasound is very sensitive in detection of thyroid nodules, enabling differentiation of solid and fluid-containing lesions. Indeterminate and non diagnostic patterns represent the main limitation of Fine Needle Aspiration (FNA) cytology of thyroid nodules, clinical and echographic features can poorly predictive of malignancy. The newly developed real-time Ultrasound Elastography (USE) has been applied to differentiate malignant from benign lesions.
\end{abstract}

Aim of Study: To evaluate indeterminate thyroid nodules by US elastography and colour Doppler study.

Material and Methods: In this study, 73 cases were included from which 57 cases were benign and 16 cases were malignant. The cases were subjected to complete U/S, Doppler examination, Micro pure imaging and US elastography the results were compared to U/S guided FNAC.

Results: The most predictive combined ultrasound features are disappearing halo sign with the appearance of dots of micro calcifications and by colour Doppler ultrasound marked intra nodular and absent or slight peri nodular blood flow represented with malignant nodules more than benign, the combination of US elastography with US findings clears that hypoechogenicity/score 4-5 was the most predictive of malignancy with sensitivity $80 \%$ and specificity $100 \%$; and accuracy $93.4 \%$.

Conclusion: US-elastography combined with colour Doppler US, has rapid and easy performance and can help to identify nodules of thyroid gland that are likely seems to be malignant.

Key Words: Thyroid elastography - Thyroid Doppler - Thyroid ultrasound.

Correspondence to: Dr. Alshaymaa Zakaria Mahmoud, The Department of Radiology, Faculty of Medicine, Tanta University

\section{Introduction}

WE can commonly find thyroid nodules in general, particularly in places with iodine-deficiency and are palpable in 5\% of people [1]. Malignant lesions represents $5 \%$ of all thyroid nodules irrespective of its size, $15-30 \%$ are known to be indeterminate or suspiciously malignant and the majority are benign in nature $[2,3]$.

Clinical assessment of thyroid nodules is very important as a firm or hard consistency suggest malignant nature and a soft consistency is associated with benign nature but it is highly dependent on the experience of the examiner [4].

Although thyroid ultrasound (US) examination is a sensitive method in detection of thyroid nodules, we can use it to differentiate between benign and malignant one but relatively in limits [5]. The best single way of differentiation is cytological examination of material obtained by Fine-Needle Aspiration (FNA) because of its high sensitivity and specificity, but still $30 \%$ of samples are non conclusive [6,7].

US elastography is a simple non invasive dynamic technique that is used in evaluation of thyroid nodules and assessment of the degree of distortion of a tissue under the application of an external force. Because softer parts of tissue deform more readily than the stiffer parts, and pathological tissues are usually harder ranging between red and blue colors. It is non stressful for patients, easy to perform, and requires not more than a few minutes of over the time of technique of single ultrasound and is a very useful examination to avoid unnecessary procedures $[8]$. 
Because of the accessibility of the gland we made external deformation of the thyroid gland using the ultrasound transducer is utilized by several groups because of the accessibility of the gland; it introduced from pulsations due to blood flow. This technique make us evaluate the tissue stiffness from the deformation rate that can be represented through colored map [9].

\section{Material and Methods}

The objective of this prospective study was to evaluate the diagnostic value of ultrasound elastography and colour Doppler ultrasonograhy in predicting malignancy in intermediate thyroid nodules, and using the histopathological cytology as the reference standard.

The study included 50 consecutive patients; 41 females and 9 males with 73 thyroid nodules, were enrolled in the study with thyroid nodules. Their ages range from 21-80 years (mean age 44 years) referred from Surgery Department to Radiology Department, Tanta University from March 2019 to January 2020, these patients signed on informed consent before starting examinations, our exclusion criteria were patients with previous partial thyroidectomy, they were examined by US B-mode, US color Doppler and US-elastography. Fine-needle aspiration biopsy were done to all patients and patients with intermediate or malignant nodules are subjected to thyroid surgery.

US elastography is a technique to assess the elasticity of tissue. The tissue of malignant thyroid nodule is harder and firmer than that of the normal thyroid parenchyma or a benign nodule. Elastography measures how much the tissue is firm and this is illustrated on an elastography map. USelastography scores were classified to five classes of tissue stiffness (class 1 for soft nodules; class 2 and 3 for nodules with an intermediate degree of stiffness; class 4 and 5 for anelastic lesions).

The ultrasonic examinations were done in three steps. Firstly B-mode ultrasound was done, secondly color Doppler was done, and thirdly realtime sonographic elastography was done in the same examination by using the same probe.

All patients were examined with a 10-13-MHz. linear transducer (Toshiba Aplio-XG machine) during the same examination by the same operator. In sonographic elastography, the deviations occurring before and after tissue compression were calculated and were displayed graphically in the elastogram.
For all patients, the US examination was started with B-mode US. The posturing of the patients for imaging was the same of that used for standard clinical thyroid gland examination: The patient was placed on his or her back with the neck slightly extended over a pillow. The transducer was applied to the hyperextended neck with chin is elevated. During B-mode US, thyroid gland lesions were cleared and the area of interest for elastography was specified. The maximum size of B-mode ultrasound images was $40 \mathrm{~mm}$ in depth and $40 \mathrm{~mm}$ in lateral width; the maximum size of the area of interest for elastography was $35 \mathrm{~mm}$ in depth and $30 \mathrm{~mm}$ in lateral width.

A good assessment of the following US criteria was done to all thyroid nodules patients: Echogenicity (hyper echoic, iso echoic, or hypo echoic with respect to normal thyroid parenchyma or surrounding muscle), presence or absence of the halo sign (A halo or hypoechoic rim surrounding a nodule represents the pseudocapsule that is caused by fibrous connective tissue) spot micro calcifications (presence of hyperechoic spots less than $2 \mathrm{~mm}$, without acoustic shadowing); and colour flow Doppler pattern that was defined as the absence of blood flow (type I), perinodular and absent or slight intranodular blood flow (type II), and marked intranodular and absent or slight perinodular blood flow (type III).

We perform US elastography during the US examination, we put the probe on the neck with light compression focusing on the box that including the nodule to evaluate it, compression was done in repeated way in a vertical direction with light pressure and then followed by decompression. We must apply and release pressure with a continuous movement performed at a right angle to the proximal plane of the lesion, avoiding lateral displacement of the transducer.

If there are multiple nodules, we must calculate the strain ratio of each nodule separately and calculate the strain index of thyroid nodule to normal thyroid parenchyma or muscle.

Acquiring measurements at the same depth of the nodule and adjacent normal thyroid parenchyma or muscle was a critical issue for strain ratio calculation.

The principle of US elastography is to obtain two ultrasonic images (before and after tissue compression by the transducer) and trace tissue.

The stiffness of thyroid nodules is subordinated to the nodule structure and cellularity. The principal 
concept of US elastography is that compression applied to the thyroid tissue produces the strain (tissue displacement in longitudinal direction) within the tissue, and the amount of strain is less in harder tissues than in softer ones. Elastography is useful in evolving benign from malignant thyroid nodules because malignant nodules are harder than the surrounding adjacent parenchyma.

Thyroid nodule can be evaluated by:

1- Evaluation based on Elasticity scores.

2- Evaluation based on strain ratio.

Elasticity scores in the thyroid nodule:

1- Low stiffness over the whole nodule; the whole nodule is regulary shaded green, as the surrounding normal thyroid tissue.

2- Low stiffness over most of the nodule; the nodule is almost completely green but with some blue spots.

3a- Low stiffness at the peripheral area with high stiffness in the center of the nodule; the central part of the nodule is blue; the peripheral part is green.

3b- High stiffness over most of the nodule; the nodule is almost completely blue but with some green spots.

4- High stiffness over the whole nodule; the whole nodule is regularly shaded blue.

5- High stiffness over the whole nodule and the tissue arround it; both the nodule and surrounding area are blue.

Ultrasound elastography can be color coded ranging between red and blue or light and dark.

\section{Evaluation depended on strain ratio:}

The strain ratio (normal tissue to lesion strain ratio) of each nodule was estimated by dividing the Strain Value (SV) of the normal tissue (which is lined by yellow circle and take number (1) by that of the nodule (which is lined by red circle and take number (2). The strain values of the normal tissue and the nodule are drawn in two curves that take the same colors of the circles. The Strain Ratio (SR) is automatically calculated using exclusive software connected to the ultrasound machine and appear in a separate curve.

Each lesion was evaluated at least three times and the average value was recorded as the final result. The mean examination time was $5-8 \mathrm{~min}$ per patient. One operator do all examinations being not aware cytology results. All images (static and dynamic images) were also recorded for a seconed skilled US examiner to review it.

All of the patients underwent ultra sound guided fine-needle aspiration biopsy within 5 days of the real-time sonographic elastographic procedure A 23 -gauge needle was used with an attached $10-\mathrm{mL}$ syringe for fine-needle aspiration biopsies. Aspiration was repeated one or two times then spicemens were collected and putted onto glass slides, smeared, and equally fixed in air and 95\% ethyl alcohol.

The cytologic diagnoses of the thyroid nodules were set side by side with real-time sonographic elastography.

\section{Results}

The study included fifty patients their ages range from 21-80 years, including nine men (3778 years) and 41 women (21-80 years). A total of 50 cases with 73 indeterminate nodules, 16 nodules $(21.9 \%)$ were proved to be malignant by histo pathology: 13 papillary thyroid carcinomas, including eight classic variants, four follicular variants, and one tall cell variant; one minimally invasive follicular carcinoma; and two medullary carcinoma. Of 73 nodules, 57 (78.1\%) were proved to be benign by histo pathology: 50 follicular adenomas, 6 hyper plastic nodules, and one colloid cyst.

Colour flow Doppler pattern that was (type I) defined as the absence of blood flow, fifteen benign nodules (26.3\%), (type II) peri nodular and absent or slight intra nodular blood flow, forty benign nodules $(70.18 \%)$ \& seven malignant nodules (43.7\%), and (type III) marked intra nodular and absent or slight peri nodular blood flow, nine malignant nodules $(56.2 \%)$ and two benign nodules $(3.51 \%)$. The pattern of intra nodular blood flow, as a solitary result, was not predictive of malignancy (sensitivity $6.7 \%$ and specificity $96.7 \%$; accuracy 67.4).

The US patterns that highly predicting malignancy were: Nodule hypoechogenicity (sensitivity $81 \%$ and specificity $62 \%$; accuracy 67.4 ), absent halo sign (sensitivity $64 \%$ and specificity $82 \%$; accuracy $53.2 \%$ ), spot microcalcifications (sensitivity $64 \%$ and specificity $72 \%$; accuracy $68.3 \%$ ), blurred or irregular margins (sensitivity $84 \%$ and specificity $62 \%$; accuracy $68 \%$ ) and an A/T of $1 \mathrm{~cm}$ or greater (sensitivity $80 \%$ and specificity $64 \%$; accuracy $67 \%$ ). The pattern of intranodular blood flow, as a solitary result, was not predictive of malignancy (sensitivity $6.7 \%$ and specificity $96.7 \%$; accuracy 67.4). 
Single US patterns was not good to predict the presence of malignancy. The echo graphic patterns combination may increase the specificity, but decreased the sensitivity of conventional US in inde-

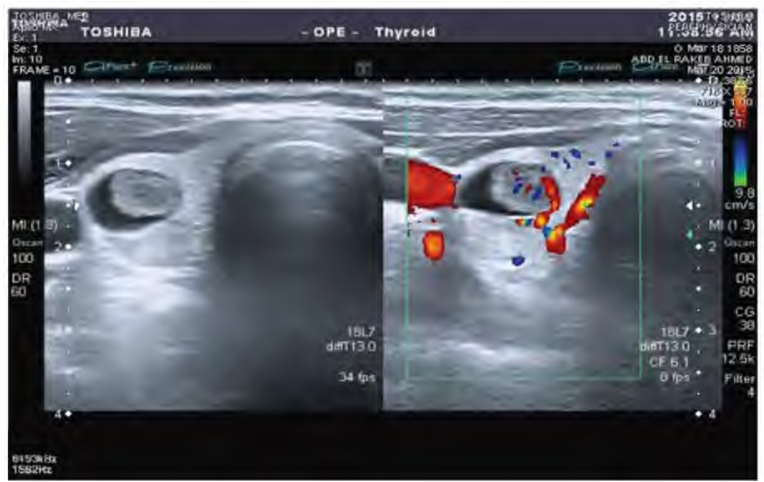

Fig. (1A): A 37 years old male patient presented by right neck swelling. (A) B mode shows acomplex predominantly solid nodule with iso echoic fairly regular outline solid content seen in the right lobe. Colour Doppler ultrasound shows central \& peri nodular vascularity.

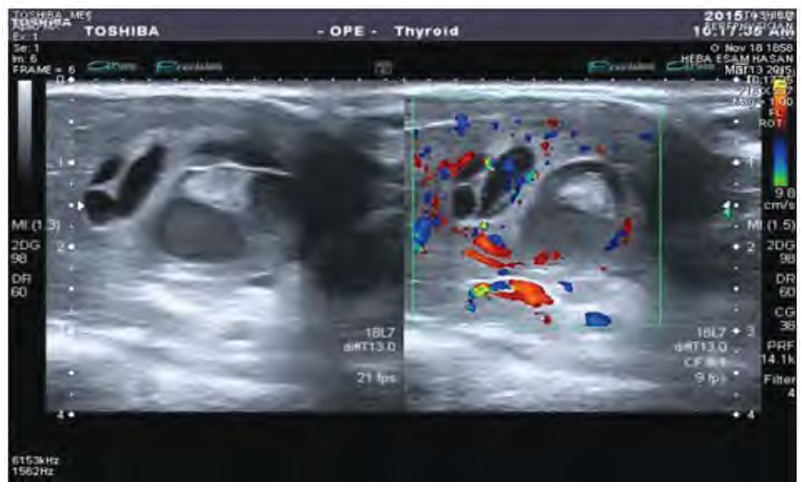

Fig. (2A): A 27 years old female patient presented with neck swelling (A) B mode shows a fairly well defined thickened wall heterogeneous mixed density nodule. Colour Doppler ultrasound shows exclusively perinodular vascularity.

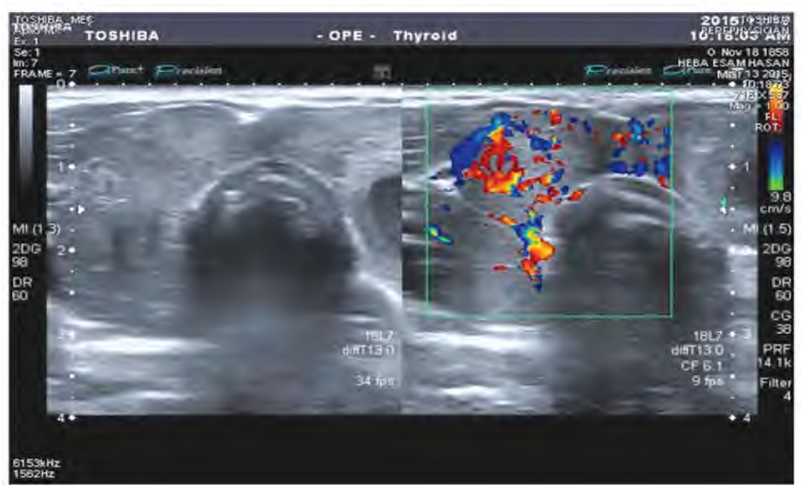

Fig. (3A): A 45 years old female patient presented with neck swelling (A) B mode shows there are multiple iso echoic fairly well defined Solid nodules, the largest seen at the right lobe. Colour Doppler ultrasound Central \& perinodular vascularity. terminate nodules. The most predictive combination was the absence of halo sign with the presence of spot micro calcifications. (Sensitivity $61 \%$, specificity $95 \% \&$ accuracy $82.2 \%$ ).

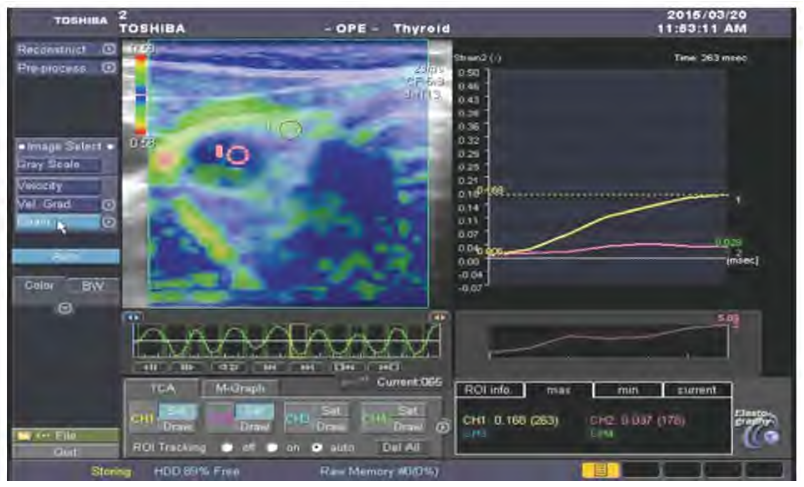

Fig. (1B): Elastography shows colour coding: Absent elasticity throughout the examined region (the entire nodule is displayed homogeneously in dark blue). Strain index: Score 4. Histopathological diagnosis: Follicular variant of papillary thyroid carcinoma.

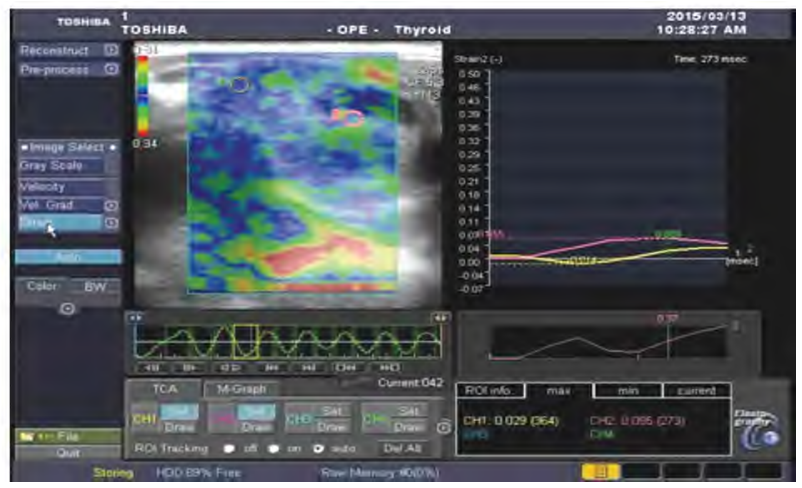

Fig. (2B): Elastography shows colour coding: Flexibility in most of the examined (almost the entire nodule is displayed in light green with some peripheral and/or central blue areas) Strain index: Score 2. Histopathological diagnosis: Colloid nodule.

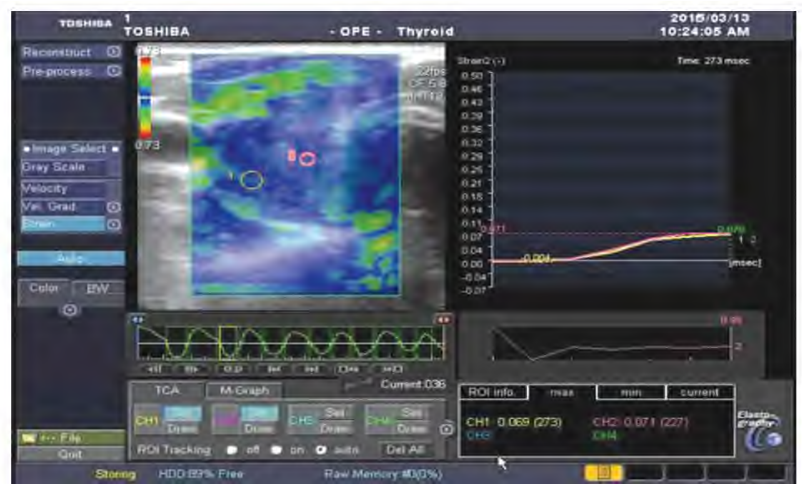

Fig. (3B): Elastography shows colour coding: Absent elasticity in most of the examined (almost the entire nodule is displayed in light blue with some regions of light green. Strain index: Score 3. Cytological findings: Hyper plastic nodule. 
Combination of elastography with US findings reveals that hypoechogenicity/score 4-5 was most predictive of malignancy with sensitivity $80 \%$ and specificity $100 \%$; and accuracy $93.4 \%$ in addition to the presence of spot microcalcifications/score 4-5 with sensitivity $66.7 \%$ and specificity $100 \%$; and accuracy $89.1 \%$ in addition to absent halo sign/score $4-5$ with sensitivity $60 \%$ and specificity 96.7\%; and accuracy $84.7 \%$.

Table (1): Predictive value of colour flow doppler in patient with thyroid nodules.

\begin{tabular}{lcccccccc}
\hline & $\begin{array}{c}\text { Benign } \\
\text { nodules }\end{array}$ & \multicolumn{2}{c}{$\begin{array}{c}\text { Malignant } \\
\text { nodules }\end{array}$} & Total & \multicolumn{2}{c}{ Chi-square } \\
\cline { 2 - 9 } & $\mathrm{N}$ & $\%$ & $\mathrm{~N}$ & $\%$ & $\mathrm{~N}$ & $\%$ & $\chi^{2}$ & $p$-value \\
\hline Type I & 15 & 26.32 & 0 & 0.00 & 15 & 20.55 & 28.628 & $<0.001^{*}$ \\
Type II & 40 & 70.18 & 7 & 43.75 & 47 & 64.38 & & \\
Type III & 2 & 3.51 & 9 & 56.25 & 11 & 15.07 & & \\
\hline Total & 57 & 100.00 & 16 & 100.00 & 73 & 100.00 & & \\
\hline
\end{tabular}

Table (2): Sensitivity, specificity and accuracy of combination of US patterns in histopathologically proved thyroid nodules.

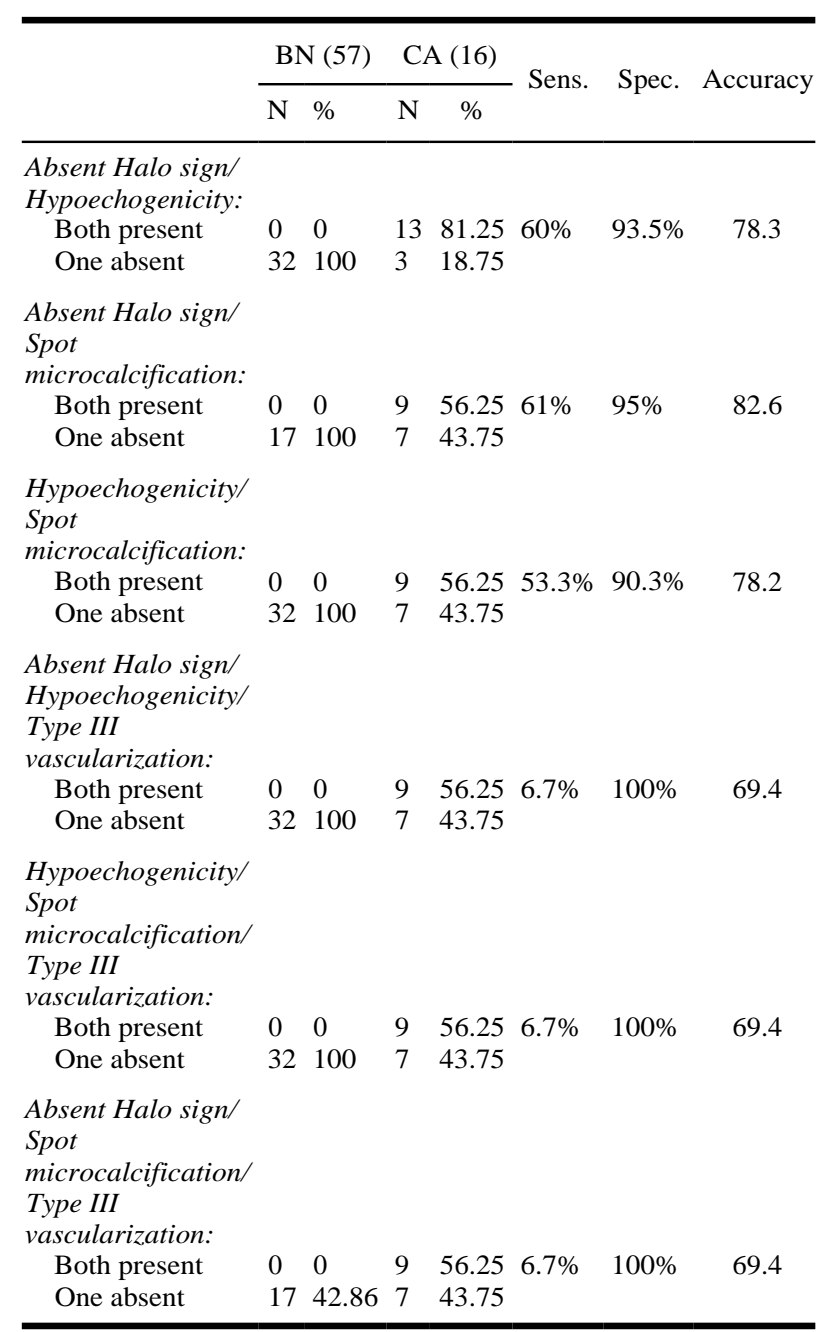

Table (3): Combined US findings with elasticity scores and strain ratio.

$\begin{array}{rrrrr}\text { BN } & \text { MN } & \text { Sens. Spec. Accuracy } \\ (57) & (16)\end{array}$

\begin{tabular}{|c|c|c|c|c|c|}
\hline \multicolumn{6}{|c|}{$\begin{array}{l}\text { Absent halo sign/score 4-5/SI } \\
>2.3 \text { : }\end{array}$} \\
\hline Both are present & & 13 & $60 \%$ & 96.7 & 84.7 \\
\hline One absent & & 3 & & & \\
\hline \multicolumn{6}{|c|}{$\begin{array}{l}\text { Present halo sign/score } 1-3 / S I \\
<2.3 \text {. }\end{array}$} \\
\hline Both are present & 40 & 1 & 40 & 19.3 & 26.1 \\
\hline One absent & 17 & & & & \\
\hline \multicolumn{6}{|c|}{ Hypoechogenicity/score 4-5/SI } \\
\hline Both are present & & 13 & 80 & 100 & 93.4 \\
\hline One absent & 32 & 3 & & & \\
\hline \multicolumn{6}{|c|}{$\begin{array}{l}\text { Absent hypoechogenicity/ } \\
\text { score } 1-3 / S I<2.3 \text { : }\end{array}$} \\
\hline Both are present & 25 & 1 & 6.7 & 38.7 & 28.3 \\
\hline One absent & 32 & 3 & & & \\
\hline \multicolumn{6}{|c|}{ Spot microcalcifications/score } \\
\hline $4-5 / S I>2.3:$ & & & & & \\
\hline Both are present & & 9 & 66.7 & 100 & 89.1 \\
\hline One absent & 17 & 5 & & & \\
\hline \multicolumn{6}{|c|}{$\begin{array}{l}\text { Absent microcalcifications/ } \\
\text { score } 1-3 / S I<2.3 \text { : }\end{array}$} \\
\hline Both are present & 27 & & 6.7 & 29 & 21.7 \\
\hline One absent & 30 & 5 & & & \\
\hline \multicolumn{6}{|c|}{ Type III vascularization/score } \\
\hline both are present & - & 9 & 6.7 & 100 & 69.7 \\
\hline One absent & 2 & 7 & & & \\
\hline
\end{tabular}

\section{Discussion}

A thyroid nodule is a discrete lesion within the thyroid gland. It may or may not be palpable. Palpable thyroid nodules are usually discovered on physical examination, but could be felt by the patient initially. Non-palpable thyroid nodules are always incidentally discovered on CT. Non-palpable nodules have the same risk of malignancy as palpable nodules of the same size [10].

In the present study, the majority $(81.25 \%)$ of thyroid cancer cases are papillary cancer. Other histologic types of thyroid cancer include follicular $(6.25 \%)$ medullary $(12.50 \%)$, in agreement with (David F 2013) [11].

Palpation is a clinical skill that give data about soft tissues stiffness using external compression for physical deformation of the tissue, elasticity measurements and stiffness evaluations of soft tissues are useful in the distinguishing tumor from inflammation or normal tissue. It is generally known that benign soft-tissue lesions are firmer than normal tissue but softer than cancers [12].

Multiple researches confirm that FNAC should be mandatory if there is ultrasound features indi- 
cating a high risk for malignancy and even further treatment such as surgery is highly recommended in these cases. These features include the presence of irregular margins, marked hypo echogenicity, micro calcifications, oval shaped nodule with more length than width, and the presence of intra nodular vascularity [13].

In the current study the most US features suggestive of malignancy in agreement with Rago et al., 2010 [14]; combination of absent halo sign with the existence spot micro calcifications and also combined absent halo sign/hypo echogenicity and all were confirmed by US elastography that revealed a score of 1-3 in all benign cases with only one case scored as score 3 and had these US suspicious features, revealed after that being a minimally invasive follicular carcinoma.

Color Doppler US is considered now the best imaging technique that evaluates thyroid nodules because it is widely available and is more practical, and many authors have shown its ability to identify lesions with more probability of malignancy with good sensitivity and specificity [15].

Chammas et al., 2005 [16] found that $89 \%$ of malignant cases had central vascularity (exclusively central or central more than peripheral). While $87.1 \%$ of benign cases were avascular or had mainly peripheral vascularity (exclusively peripheral or peripheral more than central).

In agreement with Chammas et al., 2015 [16] we notice in our study that central vascularity is found in nine malignant nodules \& two benign nodules however, perinodular blood flow is found in 47 cases from which 7 cases were malignant and 40 cases were benign. So the risk of malignancy increases as intranodular blood flow becomes more dominant.

US elastography is able to determine tissue stiffness and strain non invasively bur grey scale US does not give data about the rigidity of the nodule. Strain clears the amount of distortion; thus, soft tissue shows more strain than stiff tissue. Different levels of stiffness could be seen within the same thyroid lesion, according to the cellularity and the structure components of the nodule. Information from these studies helps to assess the relative stiffness of the lesion compared with its surrounding tissues and within itself [13].

Regarding to US elastography. Several previous studies have used ultrasound elastography for evaluation of thyroid nodules. Many of them re- ported variable sensitivity and specificity of USE for predicting malignancy.

In the study of Asteria et al., 2018 [17] they reported that the sensitivity, specificity, PPV and NPV of the USE for thyroid cancer diagnosis were $94.1 \%, 81 \%, 55.2 \%$ and $98.2 \%$, respectively and the accuracy was $83.7 \%$.

In another study of Rago et al., 2010 [14] showed sensitivity and specificity as high as $97 \%$ and $100 \%$, respectively for larger thyroid nodules by using US elastography.

The current study is in agreement with these opinions as the score 4-5 was attained in 15 of 16 malignant nodules, while the score 1-3 was detected in 58 nodule, 57 of them are proved to be benign nodules. So the scores of 1-3 with Ueno classification criteria were significantly seen in benign nodules, whereas, scores of 4 and 5 were notably seen in malignant nodules with sensitivity $93.3 \%$, specificity $100 \%$, PPV 54\%, NPV $98.2 \%$ and accuracy $97.8 \%$.

It has also been famed that arterial pulsations may bring out compression decompression movements that may produce interfering elastographic images with unneeded thyroid movement and it is difficult to limit thyroid movement [18].

The results of our study indicated that combined techniques were superior to US alone and added more remarkable value when compared with US elastography alone and these results are compatible with Mona et al., 2014 study that revealed that the mixture of elastography and grey-scale US, showed superior result in differentiating benign from malignant thyroid nodules [19].

We propose USE as a valuable method in the pre surgical risk rating of malignancy in thyroid nodules that have indeterminate or non-diagnostic cytology, high elasticity being highly related to benign histology.

We concluded that US-elastography combined with Doppler US modalities is a promising technique that is easy and fast to carry out and can help to differentiate benign from malignant thyroid nodules, it needs further studies to able to conclude about the place of elastography in thyroid nodules evaluation, versus Fine-Needle Aspiration Cytology (FNAC), the gold standard. Indeed, elastography could reduce FNAC or at least allow to select nodule's (or nodular zone's) for aspirations. 


\section{References}

1- CRISTINA ROMEI and ROSSELLA ELISEI: RET/PTC translocations and clinico-pathological features in human papillary thyroid carcinoma. Front. Endocrinol. Journal, Vol. 3 No. 54, 2012.

2- VORLÄNDER C.1, WOLFF J., SAALABIAN S., et al.: Real-time ultrasound elastography-a noninvasive diagnostic procedure for evaluating dominant thyroid nodules. Langenbecks Arch. Surg., 395 (7): 865-7, 2010.

3- WON-JIN MOON and JUNG HWAN BAEK: Ultrasonography and the Ultrasound-Based Management of Thyroid Nodules: Consensus Statement and Recommendations. Korean Journal of Radiology: 12 (1): 1-14, 2011.

4- KWAK J. and KIM E.: Ultrasound elastography for hyroid Nodules: Recent advances, ultrasonography, 33 (2): 75 $82,2014$.

5- MONPEYSSEN H., TRAMALLONI J., POIREE S., et al.: Elastography of the thyroid, Diagnostic and interventional imaging, 94 (5): 535-44, 2013.

6- RAGO T., SCUTARI M., SANTINI F., et al.: Real-time elastosonography: Useful tool for refining the presurgical diagnosis in thyroid nodules with indeterminate or nondiagnostic cytology. J. Clin. Endocrinol. Metab., 95: 527480, 2010.

7- REBECCA S. BAHN and M. REGINA CASTRO.: Approach to the Patient with Nontoxic Multinodular Goiter. Journal of Clinical Endocrinol Metabolism, 96: 1202-12, 2011.

8- RYOJI KAGOYA, HIROKO MONOBE and HITOSHI TOJIMA: Utility of elastography for differential diagnosis of benign and malignant thyroid nodules. Otolaryngol Head Neck Surg.: Vol. 143 No. 2;230-4, 2010.

9- TOMY VARGHESE: Quasi-Static Ultrasound Elastography. Ultrasound Clinical Journal, 4 (3): 323-38, 2009.

10- CIBAS E.S. and SYED A.Z.: The Bethesda System for reporting thyroid cytopathology. Am. J. Clin. Pathol., 132: 658-65, 2009.
11- DAVID F. SCHNEIDER and HERBERT CHEN: New Developments in the Diagnosis and Treatment of Thyroid Cancer. A Cancer Journal for Clinicians, Volume 63Number 6, 2013.

12- KEZHAO C. and XU H.: Ultrasound Elastography of The Thyroid: Priciples and current status, Ultrasonography, 38 (2): 106-24, 2019.

13- HENRIC P., SIGRIST R., TAKAHASHI M., et al.: Ultrasound elastography in the evaluation of thyroid nodule: Evolution of a promising diagnostic tool for predicting the risk of malignancy, Radiol. Bras., 52 (4): 120-7, 2019.

14- RAGO T., SCUTARI M., SANTINI F., LOIACONO V., et al.: Real-time elastosonography: Useful tool for refining the presurgical diagnosis in thyroid nodules with indeterminate or nondiagnostic cytology. J. Clin. Endocrinol. Metab., 95: 5274-80, 2010.

15- ZEBA AHMED and MAHIRA YUNUS: Significance of ultrasound features in predicting malignant solid thyroid nodules: Need for fine-needle aspiration. Journal of Pakistan Medical Association, 60 (10): 311-28, 2010.

16- MARIA CRISTINA CHAMMAS, RENÊ GERHARD, ILKA REGINA SOUZA De OLIVEIRA, et al.: Thyroid nodules: Evaluation with power Doppler and duplex Doppler ultrasound. Otolaryngology-Head and Neck Surgery, 162 (6): 224-45, 2015.

17- ASTERIA C., GIOVANARDI A., PIZZOCARO A., COZZAGLIO L., MORABITO A., SOMALVICO F., et al.: US-elastography in the differential diagnosis of benign and malignant thyroid nodules. Thyroid, 38 (5): 523-31, 2018.

18- DIGHE M., KIM J., LUO S. and KIM Y.: Utility of the ultrasound elastographic systolic thyroid stiffness index in reducing fine needle aspirations. J. Ultrasound Med., 29 (4): 565-74, 2010.

19- MONA A. EL-HARIRI, TAMER F. TAHA ALI, MOHAMED A. TAWAB, et al.: The clinical value of ultrasound elastography in predicting malignant thyroid nodules. The Egyptian Journal of Radiology and Nuclear Medicine Volume 45, Issue 2, Pages 353-9, 2014.

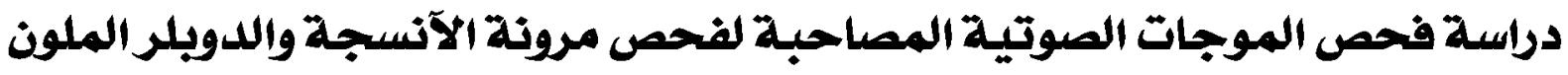

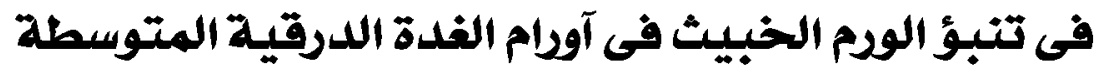

\author{
تعتبر العقد المتومة بالغدة الدرقية من آهم الآورام التى تصيب البشر خصوصاً فى المناطق التى تعانى من نقص عنصر اليود فى الجو الجى

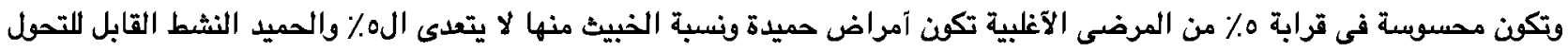

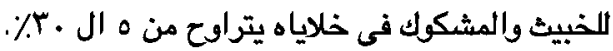 \\ ويعتبر الفحص بالموجات فوق الموتية هو الآسهل والآكثر آماناً ولكنه يفتقر إلى الدقة بملاحظة كل خاصية منفردة للتفرقة بين الآودام

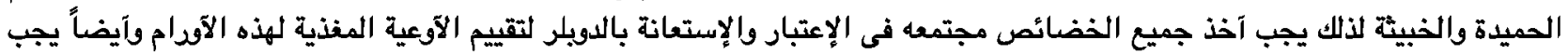

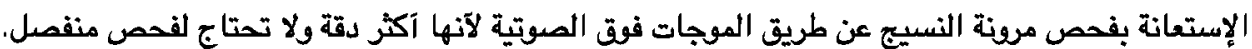

